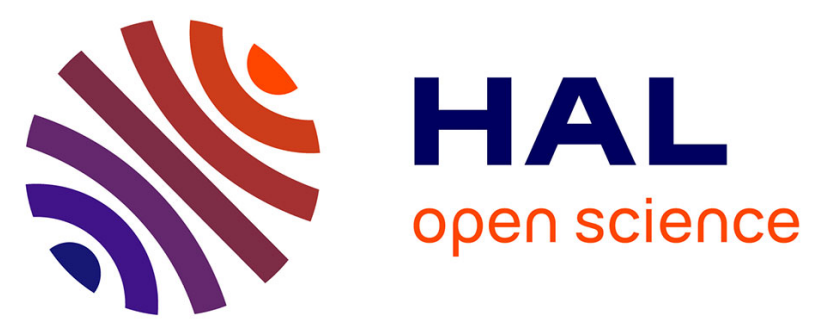

\title{
STUDY OF ELECTRICAL AND STRUCTURAL PROPERTIES OF BORON DOPED POLYSILICON FILMS WITH A LOW NITROGEN CONTENT
}

Hachemi Bouridah, Farida Mansour, Ramdane Mahamdi, Pierre Temple-Boyer

\section{- To cite this version:}

Hachemi Bouridah, Farida Mansour, Ramdane Mahamdi, Pierre Temple-Boyer. STUDY OF ELECTRICAL AND STRUCTURAL PROPERTIES OF BORON DOPED POLYSILICON FILMS WITH A LOW NITROGEN CONTENT. Journal of Materials Science, 2005, 40 (6), pp.1405-1408. 10.1007/s10853-005-0574-2 . hal-02881772

HAL Id: hal-02881772

https://hal.laas.fr/hal-02881772

Submitted on 26 Jun 2020

HAL is a multi-disciplinary open access archive for the deposit and dissemination of scientific research documents, whether they are published or not. The documents may come from teaching and research institutions in France or abroad, or from public or private research centers.
L'archive ouverte pluridisciplinaire HAL, est destinée au dépôt et à la diffusion de documents scientifiques de niveau recherche, publiés ou non, émanant des établissements d'enseignement et de recherche français ou étrangers, des laboratoires publics ou privés. 


\section{STUDY OF ELECTRICAL AND STRUCTURAL PROPERTIES OF BORON DOPED POLYSILICON FILMS WITH A LOW NITROGEN CONTENT}

Hachemi BOURIDAH ${ }^{1}$, Farida MANSOUR ${ }^{2}$, Ramdane MAHAMDI ${ }^{2}$ and Pierre TEMPLE-BOYER ${ }^{3}$

1. Département d'Electronique; Université de Jijel BP98 Ouled Aissa JIJEL 18000,Algeria. E-mail: bouridah@mail.univ-jijel.dz

2. Département d'Electronique; Université Mentouri Route d'Ain EL-Bey Constantine, Algeria.

3. LAAS-CNRS, 7 Avenue du Colonel Roche 31077 Toulouse Cedex France. 


\begin{abstract}
In this work we propose, the study of nitrogen doped Silicon films for an application as a poly-Si gate material for metal-oxide-semiconductor devices. Nitrogen doped silicon films have been deposited at amorphous phase by low-pressure chemical vapor deposition (LPCVD) from disilane $\mathrm{Si}_{2} \mathrm{H}_{6}$ and ammonia $\mathrm{NH}_{3}$ at low temperature $\left(480^{\circ} \mathrm{C}\right)$. The films with varied nitrogen contents have been boron implanted, and annealed at several annealing conditions. The influence of the annealing conditions, the nitrogen tenor and the boron dose on the electrical and the structural properties of films are investigated and correlated. Results show that the conductivity is maximal $\left(\sigma \sim 10^{2}(\Omega . c \mathrm{~m})^{-1}\right)$ for higher annealing temperature, a nitrogen content less than $2 \%$ and a strong boron dose. These results indicate that under these optimal conditions, although some nitrogen contents is present in the films, these latter have a conducting behavior. The crystallization of films was found to depend principally on the nitrogen tenor. A quasi-totally crystallization was observed for a nitrogen tenor inferior or equal to $2 \%$ and for an annealing temperature of $1100^{\circ} \mathrm{C}$ during 120 minutes. This result is in good agreement with the greatest value of the conductivity obtained under the same conditions.
\end{abstract}

Keywords: nitrogen doped silicon, conductivity, crystallization. 


\section{Introduction}

The surface $\mathrm{p}$-channel metal-oxide-semiconductor field effect transistors (p-MOSFETs) with $\mathrm{p}^{+}$ polysilicon gates offer improved short-channel and subthreshold I-V characteristics and better controllability of the threshold voltage compared with conventional buried-channel p-MOSFETs with $\mathrm{n}^{+}$polysilicon gates [1]. However, the boron used to dope the $\mathrm{p}^{+}$poly-Si gate is easy to penetrate through the gate oxide into the underlying Si substrate [2], which causes the reliability problems of devices, such as the positive shift of the threshold voltage and the degradation of the electrical characteristics of the gate oxide [3]. Recently, nitrogen introduction into the poly-Si has been reported to suppress the boron penetration and improves the gate oxide reliability [4]. However, the nitrogen degrades the electrical and the structural properties of silicon, thus we optimize in this study the experimental parameters (annealing conditions, boron dose and nitrogen tenor), which render films conducting and polycrystalline. Nitrogen doped silicon films are deposited by LPCVD at low temperature from a mixing of disilane $\left(\mathrm{Si}_{2} \mathrm{H}_{6}\right)$ and ammonia $\left(\mathrm{NH}_{3}\right)$. The use of $\mathrm{Si}_{2} \mathrm{H}_{6}$ allows a short deposition time at low temperature and a good homogeneity and uniformity of the deposited films over the whole wafer [5].

\section{Experiment}

Nitrogen doped silicon films were deposited by low-pressure chemical vapour deposition (LPCVD) from disilane $\mathrm{Si}_{2} \mathrm{H}_{6}$ and ammonia $\mathrm{NH}_{3}$ on $10 \mathrm{~cm}$ diameter, (111), oxidized (about 120nm of oxide) silicon wafers. The deposition temperature $\mathrm{T}$ and the total pressure $\mathrm{P}$ were respectively fixed to $480^{\circ} \mathrm{C}$ and 200 millitors. Deposition times were chosen in order to obtain 200nm-thick films. This deposit is followed by boron ionic implantation with two strong $10^{15}$ and $5.10^{15} \mathrm{~cm}^{-2}$ doses. The annealing after implantation is realised in a wide temperature range, which varies between 850 and $1100^{\circ} \mathrm{C}$ for two 15 and 120 minutes annealing durations, under nitrogen $\mathrm{N}_{2}$ into a conventional furnace. The electrical properties are obtained by the four-probe method. The films structures were 
analysed by scanning electron microscopy (SEM) after dipping the samples into secco etch in order to make the polysilicon grains more distinct.

\section{Results and discussion}

\subsection{Electrical characterization}

The resistivity measures are obtained by the four-probe method. Four aligned points and distant of the same spacing are applied by simple pressure to the sample to analyze. A current I is maintained constant between the two external points, this is to measure the potential difference $\mathrm{U}$ between the two internal points.

Fig. 1

The measured resistance $\mathrm{R}$ depends on the sample geometry, and on the four points positioning on this latest, because they define the field lines [6]. $\mathrm{R}$ is given by

$$
R=K \cdot \frac{U}{I}
$$

$K$ is a corrective factor. The resistivity will be evaluated from the resistance by square given by

$$
R(\Omega / \text { square })=\frac{\rho}{d}
$$

Where $\rho$ is the resistivity and $d$ the sample thickness.

Fig. 2

Fig. 3 
Fig. 2, Fig. 3, Fig. 4, show the variation of the conductivity $(\sigma=1 / \rho)$ according to the nitrogen content in the films. We notice a decrease in the conductivity when the nitrogen tenor increases from 0 to $1 \%$. Beyond this interval the conductivity tends to stabilize.

Fig. 4

The nitrogen presence in the silicon provokes the deactivation of boron, this can be explained; on the one hand, by the formation of a B-N complex [4], and on the other hand, by the weak diffusivity of nitrogen and its low solubility $[7,8]$. These results show also, the influence of the boron dose and the annealing temperature on the films conductivity, which tends to increase when these two parameters increase. The conductivity values reveal that the films containing some nitrogen amount remain resistive after thermal annealing. Thus; we increased the annealing duration to 120 minutes for a temperature of $1100^{\circ} \mathrm{C}$. A conductivity value which characterize a conducting behaviour of films $\left(\sigma \sim 10^{2}(\Omega . c \mathrm{~m})^{-1}\right)$ appeared for a nitrogen content less than $2 \%$ and a boron dose equal to $5.10^{15} \mathrm{~cm}^{-2}$, as shown in Fig. 5. This can be explained by an important boron electrical activation in the films despite the presence of some nitrogen amount.

Fig. 5

\subsection{Structural characterization}

After dipping the samples into secco etch in order to make the polysilicon grains more distinct, scanning electron microscopy observations are realised on samples annealed at a temperature of $1100^{\circ} \mathrm{C}$ during 120 minutes for two boron doses and for several nitrogen contents. All samples are characterized by a typical polycrystalline structure. As shown in Fig.6, Fig.7, Fig.8, Fig.9, Fig.10 a quasi-totally crystallization is observed for a nitrogen tenor varying from 0 to $2 \%$. The bright regions seen in the SEM photos represent the coalescence phase. During this phase, the grains increase in size and tend to gather to constitute an entirely crystallized layer. 


\section{Fig. 6}

\section{Fig. 7}

A beginning of crystallization, characterized by the grains appearance for $4 \%$ nitrogen content as shown in Fig. 11, highlights the decrease in the crystallization rate when the nitrogen content increases. As opposed to boron, which activates the crystallization when it is present in a strong dose, the nitrogen presence at high tenor in the films tends to inhibit the crystallization. This behaviour can be due to the influence of the Si-N bonds on the films crystallinity during the deposit of the films; the nitrogen presence inhibits the formation of the silicon grains [9].

Fig. 8

Fig. 9

Fig. 10

Fig. 11

\section{Conclusion}

The effects of the nitrogen tenor, the thermal annealing and the boron dose on the electrical and the structural properties of boron doped silicon films with several nitrogen tenors have been investigated. This study showed that the evolution of the electrical and the structural properties of films is strongly related to the annealing parameters, to the boron dose and to the nitrogen content. Resistivity measurements allowed us to observe an increase in the conductivity values with the increase of the boron dose. These same measurements evidenced the reduction in the conductivity of films when the nitrogen rate increases. The best electrical property $\left(\sigma \sim 10^{2}(\Omega . \mathrm{cm})^{-1}\right)$ was obtained for an annealing temperature of $1100^{\circ} \mathrm{C}$ during 120 minutes, for a boron dose of $5.10^{15} \mathrm{~cm}^{-2}$ and for a 
nitrogen quantity lower than $2 \%$. The structural characterization results indicated that the crystallinity of each film is a strong function of the nitrogen ratio. The SEM observations showed a quasi-totally crystallization of films with nitrogen contents varying from 0 to $2 \%$ and annealed at high temperature. The increase of the nitrogen tenor in the films tends to inhibit the crystallization. The results showed a good correlation between the electrical and the structural properties. Finally, the optimal conditions have been pointed out in order to obtain a conducting and a polycrystalline material, which can be used as a polysilicon gate for p- metal-oxide-semiconductor (PMOS) devices. 


\section{References}

1. S. NAKAYAMA and T. SAKAI, J. Electroch. Soc. Phys. 144 (1997) 4326.

2. H. H. TSENG, M. GLOWSKI, P. G. TOBIN and R. L. HANCE, IEEE Electron Device Lett. 13 (1992) 14

3. J.R. PFIESTER, F. K. BAKER and T. C. MELE, T. C. MELL, H.-H. TSENG, P. J TOBIN, J. D. HAYDEN, J. W. MILLER, C. D. GUNDERSON and L. C. PARILlO, IEEE Transaction On Electron Devices. 37 (1990) 1842.

4. T. CHAO, M. C. LIAW, C. H. CHU and C. Y. CHANG, Appl.Phys.Lett. 69 (1996) 1781.

5. P. TEMPLE BOYER, F. OLIVIE, K. KASSMI, E. SCHEID, G. SARRABAYROUSE and A. MARTINEZ, Solid-State Electronics. 41 (1997) 951.

6. M. YAMASHITA, T. NICHII, H.KURIHARA, H. ENJOJI and A. IWATA, Japanese Journal of Applied Physic. 29 (1990) 776.

7. P. V. PAVLOV, E. I. ZORIN and D. I. TELEBANM, Phys. Status Solid. A 35 (1976) 11.

8. S. NAKAYAMA and T. SAKAI, J.Appl.Phys. 79 (1996) 4024.

9. W.Q. HAN, G.R. HAN, S.S.FAN and B.L.GU, Chin.Phys.Lett. 14 (1997) 682. 


\section{Figures captions}

Fig.1. Resistivity measurement with the four-probe method

Fig. 2. Conductivity variation versus nitrogen ratio

Fig. 3. Conductivity variation versus nitrogen ratio

Fig. 4. Conductivity variation versus nitrogen ratio

Fig. 5. Conductivity variation versus nitrogen ratio

Fig.6. SEM image of film after a $2 \mathrm{~h}$ anneal at $1100^{\circ} \mathrm{C}$ with $10^{15} \mathrm{~cm}^{-2}$ boron dose and $0 \%$ nitrogen ratio

Fig.7. SEM image of film after a $2 \mathrm{~h}$ anneal at $1100^{\circ} \mathrm{C}$ with $5.10^{15} \mathrm{~cm}^{-2}$ boron dose and $0 \%$ nitrogen ratio

Fig.8. SEM image of film after a $2 \mathrm{~h}$ anneal at $1100^{\circ} \mathrm{C}$ with $10^{15} \mathrm{~cm}^{-2}$ boron dose and $1 \%$ nitrogen ratio

Fig.9. SEM image of film after a $2 \mathrm{~h}$ anneal at $1100^{\circ} \mathrm{C}$ with $5.10^{15} \mathrm{~cm}^{-2}$ boron dose and $1 \%$ nitrogen ratio

Fig.10. SEM image of film after a $2 \mathrm{~h}$ anneal at $1100^{\circ} \mathrm{C}$ with $5.10^{15} \mathrm{~cm}^{-2}$ boron dose and $2 \%$ nitrogen ratio

Fig.11. SEM image of film after a $2 \mathrm{~h}$ anneal at $1100^{\circ} \mathrm{C}$ with $5.10^{15} \mathrm{~cm}^{-2}$ boron dose and $4 \%$ nitrogen ratio 


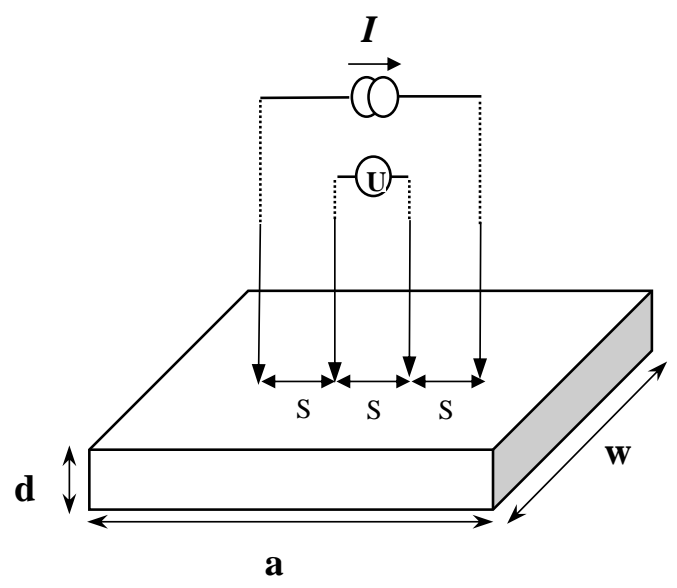

Fig. 1 


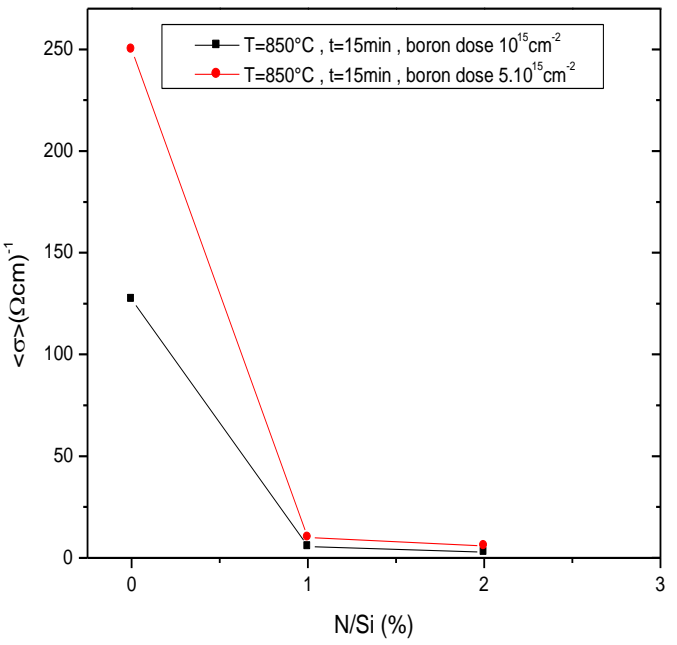

Fig. 2 


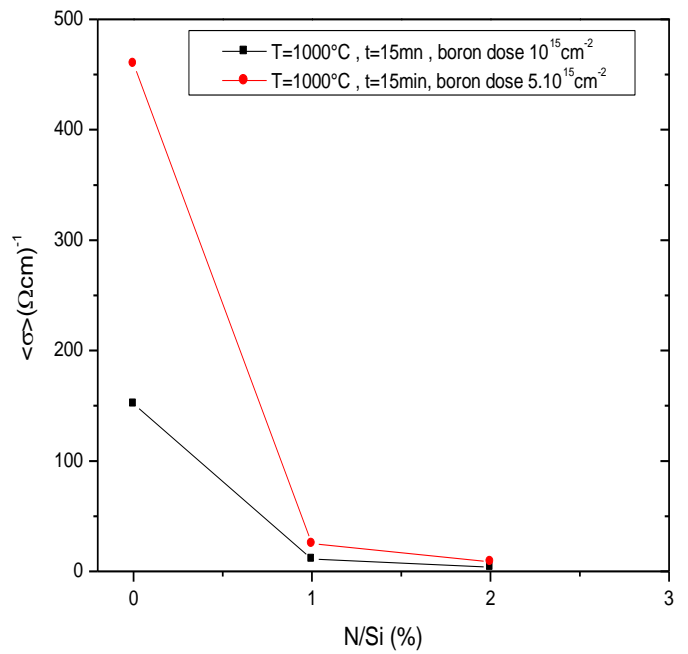

Fig. 3 


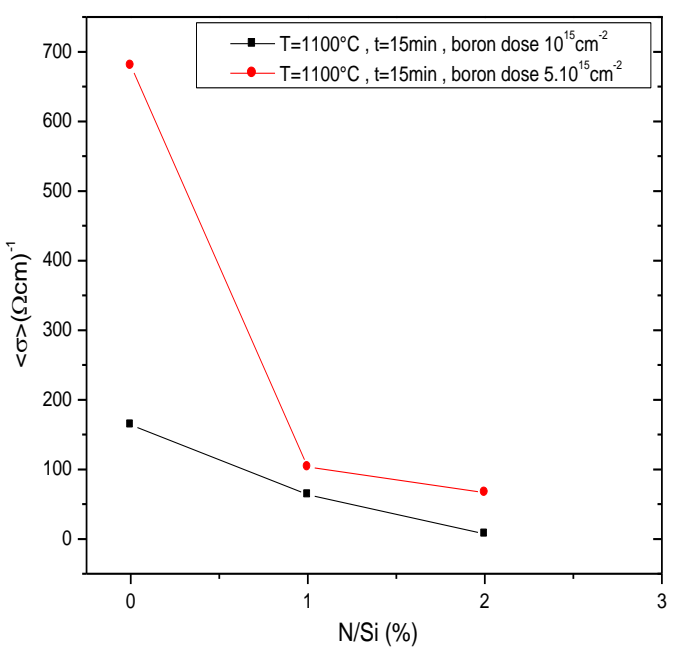

Fig. 4 


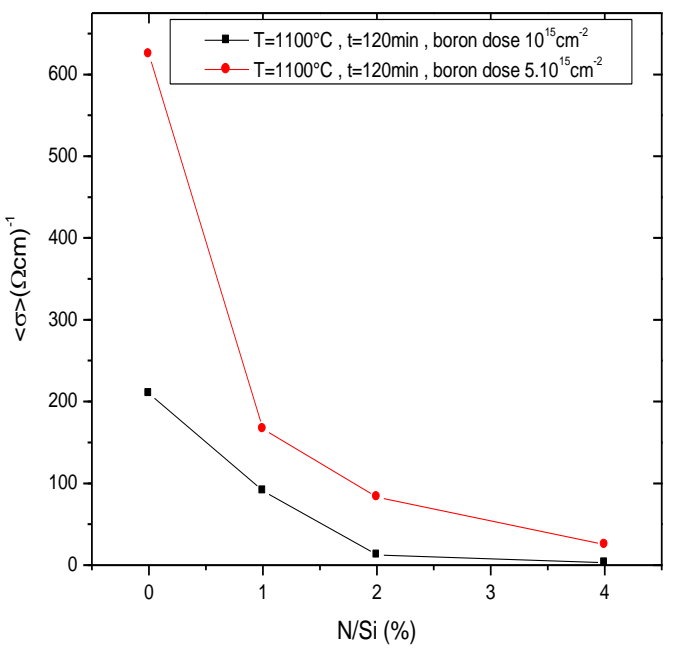

Fig. 5 


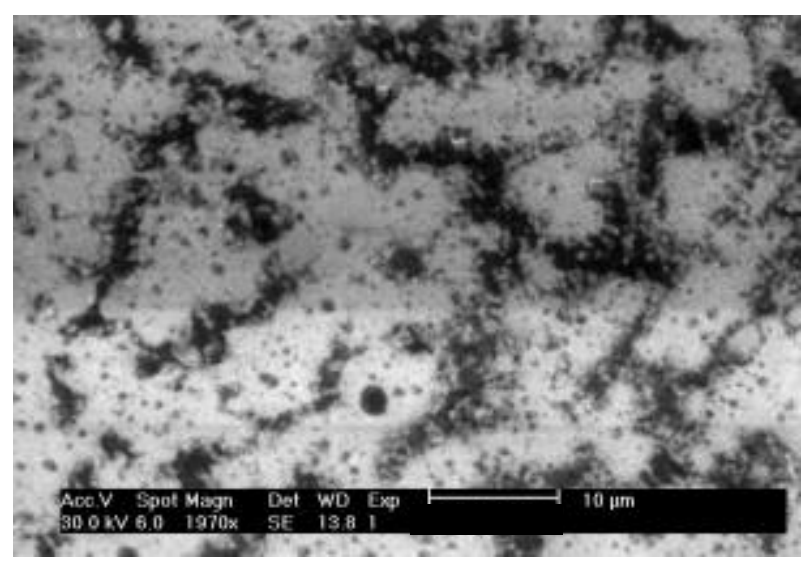

Fig. 6 


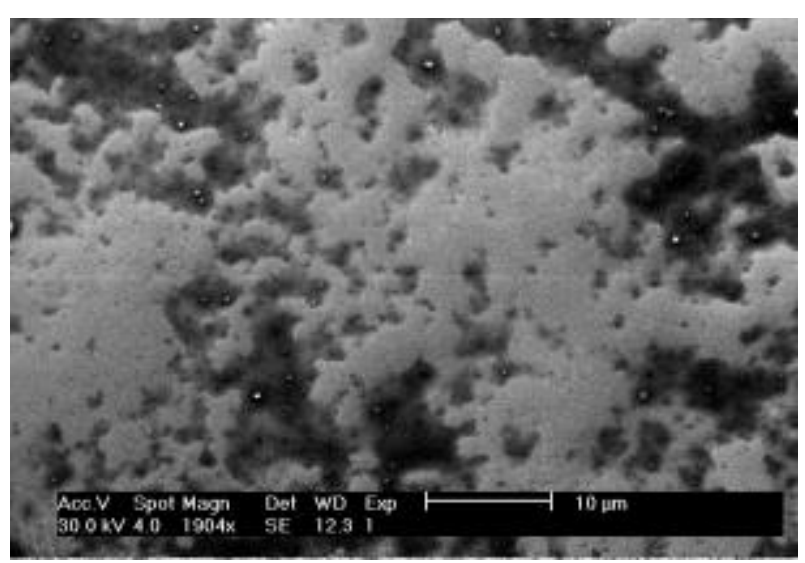

Fig. 7 


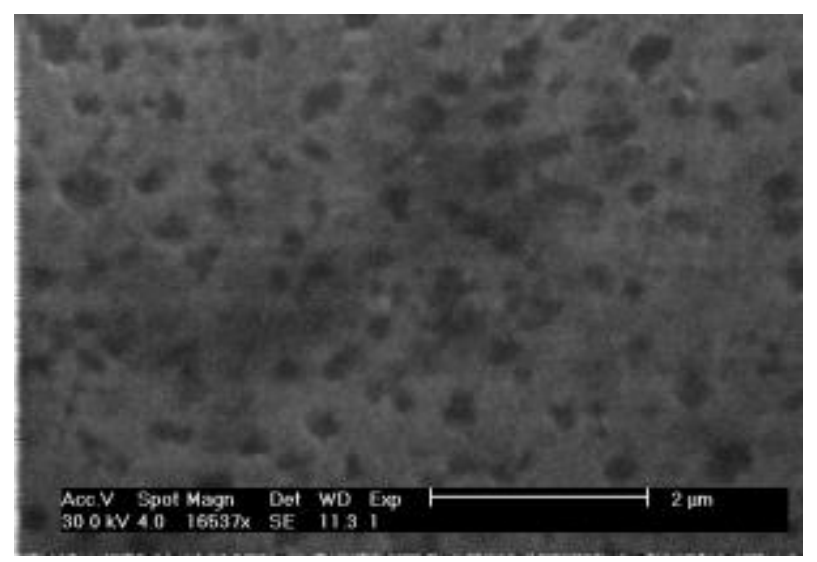

Fig. 8 


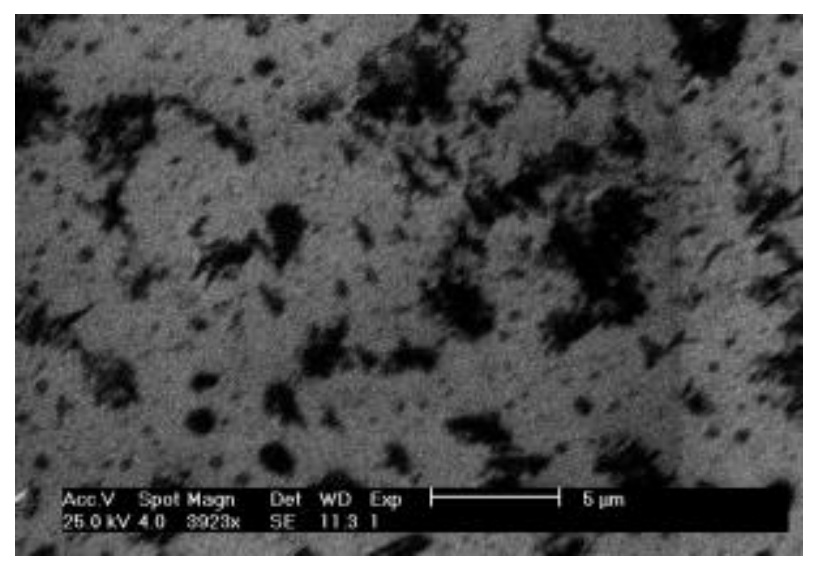

Fig. 9 


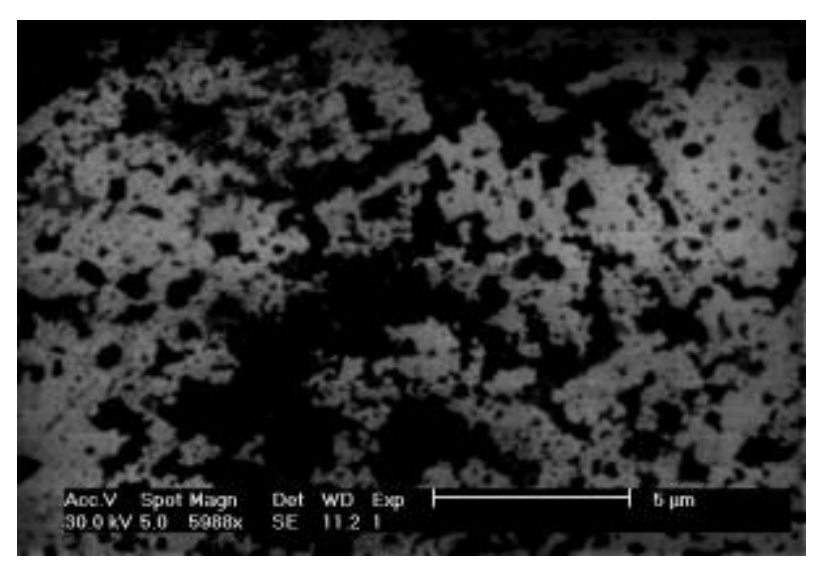

Fig. 10 


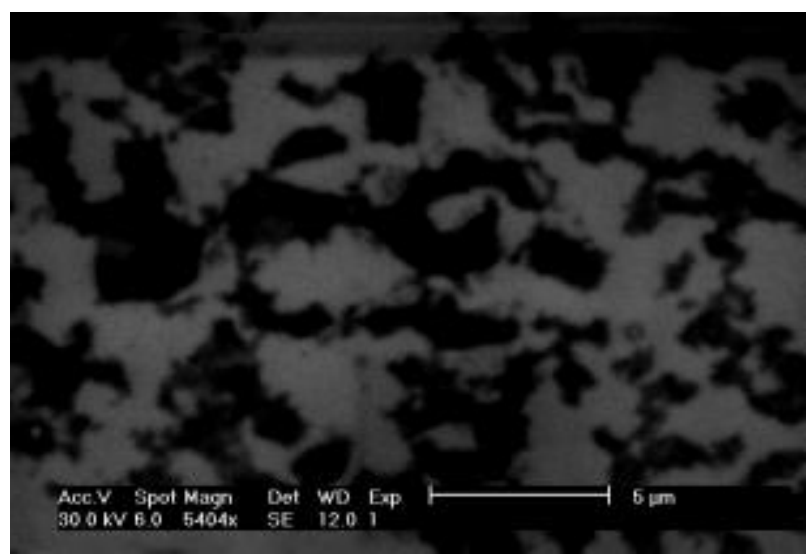

Fig. 11 